\title{
Self-assembled nanofilm of 1,2-dihydro-3-(octadecylthio)benzotriazine on copper for corrosion protection
}

\author{
B V APPA RAO*, MD YAKUB IQBAL, M NARSIHMA REDDY and K CHAITANYA KUMAR \\ Department of Chemistry, National Institute of Technology Warangal (NITW), Warangal 506 004, India
}

MS received 24 September 2012; revised 6 February 2013

\begin{abstract}
The self-assembled nanofilm of 1,2-dihydro-3-(octadecylthio)benzotriazine (DOTBT) was formed on fresh copper surface obtained by etching with $7 \mathrm{~N}$ nitric acid at a room temperature of $30{ }^{\circ} \mathrm{C}$. The conditions for formation of the DOTBT nanofilm have been optimized by electrochemical impedance and electrochemical quartz crystal nanobalance (EQCN) studies. The DOTBT nanofilm on copper surface was characterized by contact-angle measurement, X-ray photoelectron spectra (XPS), reflection absorption FTIR spectra and atomic force micrographs (AFM). It is inferred that formation of DOTBT film is due to chemisorption of DOTBT on copper surface through nitrogen and subsequent complex formation between DOTBT and $\mathrm{Cu}^{+}$ions. Corrosion protection ability of DOTBT nanofilm was evaluated in dilute aqueous $\mathrm{NaCl}$ solution using electrochemical impedance, potentiodynamic polarization, weight-loss and XPS studies. These studies inferred that the DOTBT film protects effectively copper from corrosion. Potentiodynamic polarization studies revealed that the DOTBT film inhibits corrosion by controlling the cathodic reaction. The mechanism of corrosion protection of copper by DOTBT nanofilm is discussed in this paper.
\end{abstract}

Keywords. Copper; benzotriazine; self-assembled nanofilm; impedance; EQCN; AFM.

\section{Introduction}

Copper is an important metal used in microelectronics, due to its high thermal and electrical conductivity (Murarka 1997; Rose 2002). The main applications of copper in microelectronic packaging are in lead frames, inter-connection wires, foils for flexible circuits, heat sinks, wire bonding and soldering. However, the applications of copper are limited by corrosion of copper forming an oxide film. Therefore, corrosion protection of copper is of great relevance in microelectronic packaging industry.

Self-assembled monolayers (SAMs) are dense and ordered thin films (Wang et al 2002), which act as effective barriers and protect the metals against corrosion. It has been reported that alkanethiols adsorbed on copper surface form densely packed SAMs, which retard the oxidation of copper surface in air (Laibinis and Whitesides 1992). Corrosion protection of copper by self-assembled alkanethiol monolayer in $0.5 \mathrm{M} \mathrm{NaCl}$ solution has been reported (Feng et al 1997). The maximum protection efficiency of copper corrosion in $0.5 \mathrm{M} \mathrm{Na}_{2} \mathrm{SO}_{4}$ solution using octadecanethiol SAM was reported as $80 \cdot 3 \%$ (Yamamoto et al 1993). Self-assembled nanofilms of Schiff bases on copper surfaces were formed by the interaction of copper with nitrogen present in the Schiff base molecules (Quan et al 2001, 2002). Heterocyclic compounds containing nitrogen and sulfur atoms are widely used as corrosion inhibitors (Wang et al 2002).

\footnotetext{
*Author for correspondence (boyapativapparao@ rediffmail.com)
}

So far, only a few studies on corrosion protection of copper using SAMs of heterocyclic organic compounds containing long alkyl chains have been reported in the literature. Corrosion protection of copper using the SAMs of 2(octadecylthio)benzothiazole (Appa Rao et al 2009) and of 5-methoxy-2-(octadecylthio)benzimidazole (Appa Rao et al 2010) has been reported. However, no studies have been reported so far on corrosion protection of copper by selfassembly of heterocyclic organic molecules containing three nitrogen atoms and one sulfur atom with a long hydrocarbon chain. Therefore, it was of interest to study the corrosion protection efficiency of the nanofilm of a heterocyclic organic molecule of a different moiety namely, 1,2-dihydro3-(octadecylthio)benzotriazine (DOTBT), which contains three nitrogen atoms and one sulfur atom in order to facilitate chemisorption on copper surface and subsequent chelation with copper ions to form a protective film. It also consists of a long hydrocarbon chain to make the film hydrophobic. It was of interest to investigate whether the nanofilm can be formed on copper surface using this molecule and if formed, whether the film has the ability to protect copper from corrosion in an aggressive environment like aqueous $\mathrm{NaCl}$ solution.

\section{Experimental}

\subsection{Materials}

DOTBT was synthesized from equimolar amounts of 1bromo-octadecane and benzothiazole-2-thiol as per the procedure available in the literature (Rao and Kumar 2002). All 
the chemicals were of A.R. grade and were purchased from Qualigens Chemicals, India. Differential scanning calorimetry (DSC) and ${ }^{1} \mathrm{H}$ NMR technique were used for characterization of DOTBT. Exactly $260 \mathrm{mg}$ of DOTBT was dissolved in $250 \mathrm{~mL}$ methanol to get $2.5 \mathrm{mM}$ solution. The solutions of $1.0,1.5$ and $2.0 \mathrm{mM}$ were prepared by dilution from $2.5 \mathrm{mM}$ solution.

Polycrystalline copper specimens of different dimensions were made from a copper sheet of purity $99.9 \%$. For electrochemical impedance studies and potentiodynamic polarization studies, copper specimens with dimensions of $4.0 \times$ $1.0 \times 0.2 \mathrm{~cm}$ were used and only $1 \mathrm{~cm}^{2}$ area was exposed to the electrolyte, while the remaining area was insulated with epoxy resin. For weight loss studies also, the specimens of the dimensions, $4.0 \times 1.0 \times 0.2 \mathrm{~cm}$ were used. For surface analytical studies, $1.0 \times 1.0 \times 0.2 \mathrm{~cm}$ specimens were used. These specimens were polished to mirror finish using $1 / 0$, 2/0, 3/0 and 4/0 grade emery papers and alumina powder on rotating disk and then degreased with acetone. The specimens were washed with double-distilled water and dried in nitrogen atmosphere for $20 \mathrm{~min}$. For studies using electrochemical quartz crystal nanobalance, copper quartz crystals of $0.20 \mathrm{~cm}^{2}$ area were used.

\subsection{Formation of self-assembled nanofilm}

Solubility of DOTBT was tested in the organic solvents such as acetone, chloroform, methanol, ethyl acetate and $n$-hexane. It was observed that DOTBT is soluble only in methanol and the solubility is very less in methanol. Therefore, methanol was chosen as the solvent for formation of DOTBT nanofilm on copper surface. The polished copper specimens were etched with $7 \mathrm{~N}$ nitric acid for $30 \mathrm{~s}$, washed first with triple-distilled water and then with methanol. The metal specimens were immediately immersed in different concentrations of $100 \mathrm{~mL}$ of DOTBT solution in methanol for various immersion periods.

\subsection{Electrochemical impedance studies}

Electrochemical impedance studies (EIS) were carried out in a three-electrode cell assembly using an electrochemical workstation model IM6e ZAHNER elektrik, Germany. These studies were first carried out in order to develop the optimum conditions for the formation of protective DOTBT film on copper surface. The studies were carried out at an open circuit potential (OCP) in the frequency range from $60 \mathrm{kHz}$ to $10 \mathrm{mHz}$ with a sinusoidal potential perturbation of $\pm 5 \mathrm{mV}$ in amplitude. Impedance studies were also carried out in order to evaluate the corrosion protection ability of DOTBT nanofilm in aqueous $\mathrm{NaCl}$ environment at different concentrations $(0 \cdot 02-0 \cdot 20 \mathrm{M})$, at different immersion periods $(0 \cdot 5-24 \mathrm{~h})$ and at different temperatures $\left(30-60{ }^{\circ} \mathrm{C}\right)$. In these studies, the bare copper specimen or copper specimen covered by DOTBT film was used as the working electrode. A platinum electrode was used as the counter electrode and the reference electrode was $\mathrm{Ag} / \mathrm{AgCl} / 1 \mathrm{M} \mathrm{KCl}$ electrode. Inhibition efficiencies were calculated from the impedance data. Potentiodynamic polarization studies were also carried out by using the same electrochemical workstation described above at different concentrations of $\mathrm{NaCl}$ in the range of $0.02-0.20 \mathrm{M}$. The polarization curves were recorded in the potential range of $-0.500-+0.200 \mathrm{~V}$ vs $\mathrm{Ag} / \mathrm{AgCl}$ at a scan rate of $1 \mathrm{mVs}^{-1}$. Electrochemical quartz crystal nano balance system, model Elchema EQCN-700 was used for recording mass changes during the formation of DOTBT nanofilm on AT-cut copper quartz crystal with $10 \mathrm{MHz}$ nominal frequency. After the film formation was complete, mass change as a function of immersion period was recorded by immersing the nanofilm covered copper quartz crystal in $0.02 \mathrm{M} \mathrm{NaCl}$ solution.

\subsection{Weight-loss studies}

The bare copper specimens and the copper specimens covered with DOTBT nanofilm were immersed in $0.02 \mathrm{M} \mathrm{NaCl}$ solution for a period of 3 days. The weights of the specimens before and after immersion were recorded by using an electronic balance with a readability of $0.01 \mathrm{mg}$. From the weight-loss data, the corrosion rates and inhibition efficiencies were calculated. The studies were carried out in triplicate. The relative standard error in the corrosion rate determination is of the order of $2 \%$ or less (Freeman and Silverman 1992).

\subsection{Surface analytical studies}

Reflection absorption FTIR spectra for bare copper and copper covered with DOTBT nanofilm were recorded in single reflection mode using FTIR spectrometer, model ThermoNicolet Nexus 670 of the Thermo Electron Corporation, USA in the spectral range of $400-4000 \mathrm{~cm}^{-1}$ with a resolution of $4 \mathrm{~cm}^{-1}$. This FTIR instrument has $\mathrm{KBr}$ window and $\mathrm{XT}-\mathrm{KBr}$ beam splitter and lowest possible wavenumber is $400 \mathrm{~cm}^{-1}$. Bare copper and DOTBT nanofilm covered copper specimens were mounted on the reflection accessory and the plane polarized light was incident at a grazing angle of $85^{\circ}$ from the normal surface. The sample compartment was continuously purged with nitrogen during the measurement. The surface analysis of bare copper and DOTBT nanofilm covered copper was also carried out using the X-ray photoelectron spectrometer, ESCA Kratos model AXIS-165, with $\mathrm{MgK} \alpha$ radiation $(1253.6 \mathrm{eV}$ ) and energy resolution of $0 \cdot 1 \mathrm{eV}$. Computer deconvolution was applied to detect the elemental peaks of copper, oxygen, carbon, nitrogen and sulfur present in the nanofilm. XPS studies were also used to analyse the nature of the surface films in the presence of a corrosive environment i.e. 0.02 $\mathrm{M} \mathrm{NaCl}$. Veeco Nanoscope IV multimode AFM was used for studying the morphology of copper surface covered with nanofilm. The AFM was used in the contact mode between a silicon nitride tip attached to a micro cantilever and the surface of the sample. 


\subsection{Contact-angle measurements}

Contact-angle measurements for bare copper and copper covered with DOTBT nanofilm were made by sessile water drop method using a contact-angle measuring system, model G10, Kruss, Germany. The measurements were carried out at about $30{ }^{\circ} \mathrm{C}$ in air.

\subsection{Quantum chemical calculations}

Quantum chemical calculations were carried out using semiempirical AM1 molecular orbital method in the MOPAC program using Chem3D Ultra Molecular Modelling and Analysis software. $E_{\mathrm{HOMO}}, E_{\mathrm{LUMO}}, \Delta E$, net atomic charges on each of the elements of DOTBT and the total ring charge were obtained from these calculations.

\section{Results and discussion}

\subsection{Optimum conditions for formation of DOTBT nanofilm}

The best immersion time was reported to be more than $20 \mathrm{~h}$ for the formation of nanofilm of Schiff base on copper surface (Quan et al 2001). Our results also showed that an immersion period of $24 \mathrm{~h}$ facilitates the formation of good protective film. Therefore, in the present study, an immersion period of $24 \mathrm{~h}$ was fixed initially and the concentration of DOTBT was varied from 1.0 to $2.5 \mathrm{mM}$ (solubility limit).

Nyquist and Bode plots for DOTBT modified copper electrodes at different concentrations of DOTBT $(1 \cdot 0-2.5 \mathrm{mM})$ are obtained in $300 \mathrm{ppm}$ chloride environment. Bode plots provide more valuable information than Nyquist plots. Hence, only Bode plots are presented in figure 1. Considering the phase angle vs frequency plot, with an increase in concentration of DOTBT from 1.0 to $2.5 \mathrm{mM}$, the phase angle

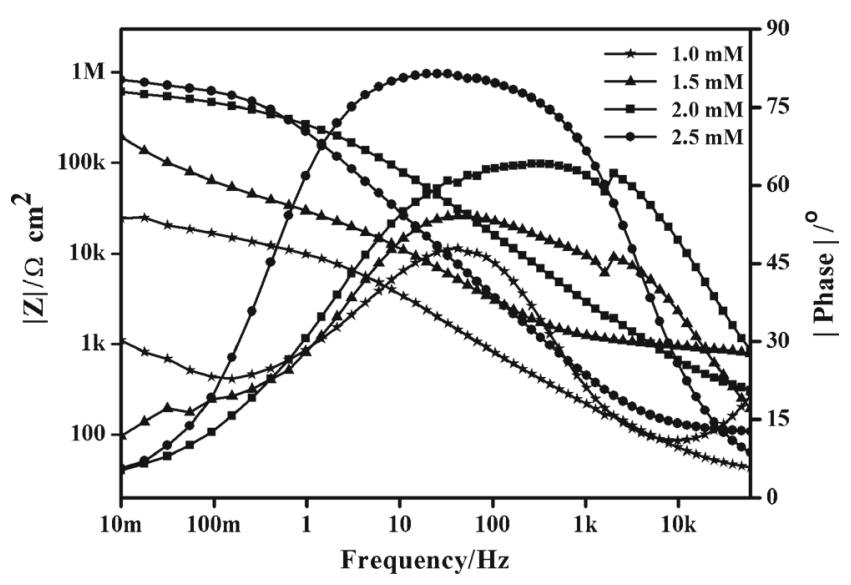

Figure 1. Bode plot of copper covered with DOTBT nanofilm formed in different concentrations of DOTBT (environment: 300 ppm chloride, temperature: $30^{\circ} \mathrm{C}$ ). maximum is increased from 46 to $85^{\circ}$ and it is more broadened. This result reveals that the DOTBT nanofilm is close to capacitive behaviour. The Nyquist plots (not shown) at higher concentrations show the absence of Warburg behaviour. The corresponding impedance parameters are obtained using the equivalent circuit models shown in figure 2 ( $a$ and $b$ ). The circuit shown in figure 2(a), which contains Warburg element, is used in the case of DOTBT film covered copper, where the Warburg impedance is seen. A constant phase element (CPE) was used as a substitute for the doublelayer capacitance in the equivalent circuits in order to fit the impedance data more accurately (Scheider 1975; Wu et al 1999). The CPE is a special element, whose value is a function of the angular frequency $(w)$, and whose phase is independent of the frequency. Its admittance and impedance are respectively, expressed as

$$
Y_{\mathrm{CPE}}=Y_{0}(j w)^{-n},
$$

$$
Z_{\mathrm{CPE}}=1 / Y_{0}(j w)^{-n},
$$

where $Y_{0}$ is the magnitude of the CPE, $j$ the imaginary number $\left(j=(-1)^{1 / 2}\right), w$ the angular frequency and $n$ the exponential term $(0 \leq n \leq 1)$ of the CPE. $n$ value indicates the roughness of the electrode. The lower the value of $n$, the rougher is the electrode surface. The lower value of $n$ also relates to the inherent physical and chemical heterogeneous nature of the solid surface (Mc Cafferty 1997), the presence of a porous corrosion product layer (Touzet et al 1993) and the non-uniform distribution of current density on the surface (Macdonald et al 1982). If $n=1$, the impedance of a CPE is identical to the impedance of the ideal capacitor.

The charge transfer resistance $\left(R_{\mathrm{ct}}\right)$ and the film resistance $\left(R_{\text {film }}\right)$ throw more light on the protective nature of the nanofilm. The results given in table 1 reveal that the $R_{\text {ct }}$ and $R_{\text {film }}$ values are the highest and the CPE values are the lowest in the case of film formed from $2.5 \mathrm{mM}$ concentration of DOTBT. Interestingly, the $n$ value is close to 1 . Therefore, $2.5 \mathrm{mM}$ concentration is chosen as the optimum concentration for formation of dense and protective film.

By fixing the concentration of DOTBT solution as $2.5 \mathrm{mM}$, DOTBT nanofilms are formed on copper surface at different immersion periods in the range of 3-24 h. The Bode plots of the DOTBT modified copper electrodes at different immersion periods are obtained in $300 \mathrm{ppm}$ chloride environment and are shown in figure 3 . The corresponding impedance parameters are shown in table 2 . The phase angle vs frequency plot reveals that at higher immersion period of $24 \mathrm{~h}$, the phase angle maximum is the highest and the $|Z|$ vs $f$ plot shows that total impedance is increased with increase in immersion period. For example, after $24 \mathrm{~h}$ immersion period, the $R_{\mathrm{ct}}$ and $R_{\text {film }}$ values are increased to very large values of 721.3 and $70.22 \mathrm{k} \Omega \mathrm{cm}^{2}$, respectively. Both

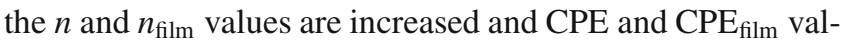
ues are decreased. All these observations reveal that the optimum immersion time for the formation of protective DOTBT nanofilm is $24 \mathrm{~h}$. 


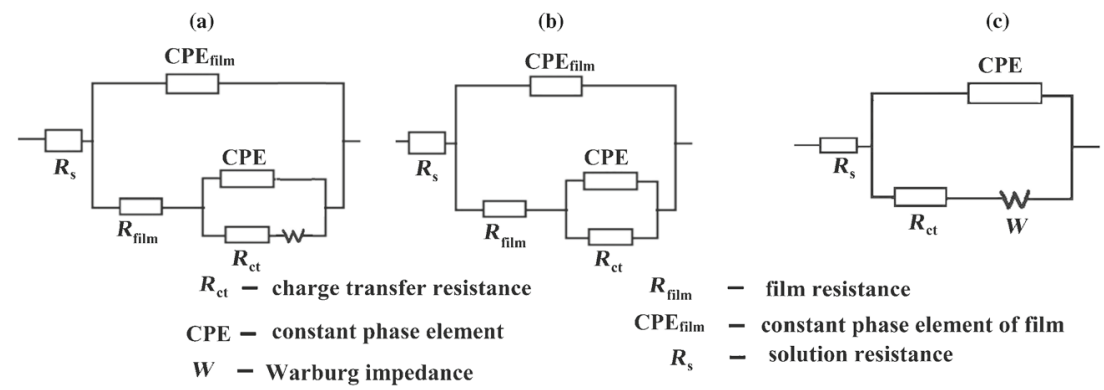

Figure 2. Equivalent circuits used in impedance measurements of (a) copper electrode covered with DOTBT nanofilm with Warburg, (b) copper electrode covered with DOTBT nanofilm and (c) bare copper electrode.

Table 1. Impedance parameters of copper covered with DOTBT nanofilm formed in different concentrations of DOTBT (environment: 300 ppm chloride, immersion period: $0.5 \mathrm{~h}$, temperature: $30^{\circ} \mathrm{C}$ ).

\begin{tabular}{|c|c|c|c|c|c|c|c|}
\hline S. no. & $\begin{array}{c}\text { Concentration } \\
\text { of DOTBT }(\mathrm{mM})\end{array}$ & $\begin{array}{c}R_{\mathrm{ct}} \\
\left(\mathrm{k} \Omega \mathrm{cm}^{2}\right)\end{array}$ & $\begin{array}{c}\mathrm{CPE} \\
\left(\mu \mathrm{F} / \mathrm{cm}^{2}\right)\end{array}$ & $n$ & $\begin{array}{c}R_{\text {film }} \\
\left(\mathrm{k} \Omega \mathrm{cm}^{2}\right)\end{array}$ & $\begin{array}{l}\mathrm{CPE}_{\mathrm{film}} \\
\left(\mu \mathrm{F} / \mathrm{cm}^{2}\right)\end{array}$ & $n_{\text {film }}$ \\
\hline 1 & 1.0 & $20 \cdot 26$ & 0.514 & 0.55 & $8 \cdot 13$ & 0.769 & 0.64 \\
\hline 2 & 1.5 & $40 \cdot 53$ & 0.276 & 0.84 & $20 \cdot 2$ & 0.041 & 0.67 \\
\hline 3 & $2 \cdot 0$ & $556 \cdot 1$ & 0.034 & 0.89 & 33.6 & 0.017 & 0.70 \\
\hline 4 & 2.5 & $721 \cdot 3$ & 0.033 & 0.93 & $70 \cdot 2$ & 0.022 & 0.73 \\
\hline
\end{tabular}

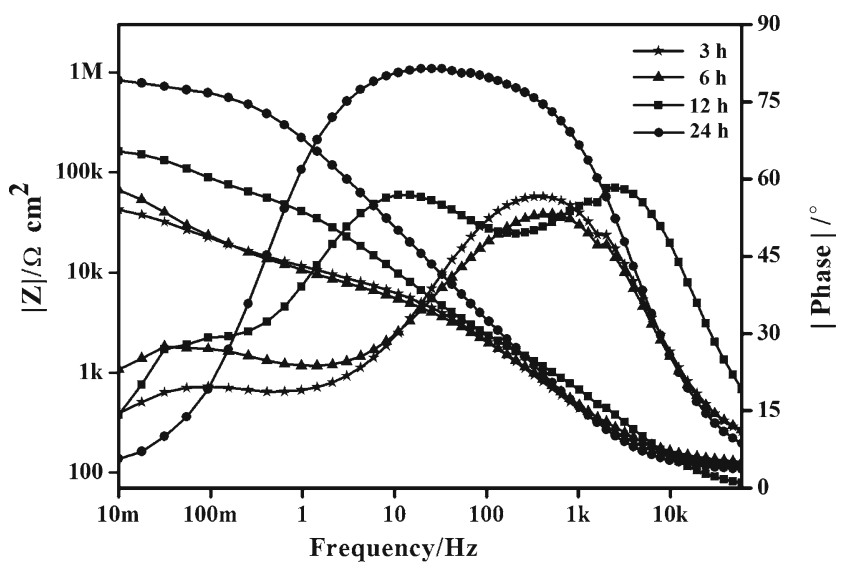

Figure 3. Bode plot of copper covered with DOTBT nanofilm formed in $2.5 \mathrm{mM}$ DOTBT at different immersion periods (environment: 300 ppm chloride, temperature: $30{ }^{\circ} \mathrm{C}$ ).

Figure 4(a and b) shows the mass change vs time plots obtained from the EQCN experiment in the case of blank (in methanol) and with DOTBT film, respectively. The blank curve shows negligible mass change with time, which indicates that there is not much adsorption of methanol on the copper surface. The curve with DOTBT film shows an initial increase in mass in the first $60 \mathrm{~min}$ followed by a tendency towards saturation with a further increase in time up to $105 \mathrm{~min}$. The increase in mass of the copper quartz crystal is due to the formation of nanofilm of DOTBT on its surface. It is known that the formation of the self-assembled monolayer on copper surface occurs in two steps (Brzoska et al 1992). In the first step, the organic molecule chemisorbs on the copper surface and in the second step, it rearranges to form an ordered monolayer. Obviously, the first step involving chemisorption takes relatively less time and the second step involving the rearrangement of the organic molecules in the SAM takes relatively longer time. This is evidenced by the increase in charge transfer resistance of the nanofilm formed after $24 \mathrm{~h}$ immersion time. Therefore, an immersion period of $24 \mathrm{~h}$ is fixed as another optimum condition for formation of DOTBT nanofilm.

\subsection{Characterization of DOTBT nanofilm}

3.2a Contact angle measurements: The contact angle values for bare copper and DOTBT modified copper are found to be 78 and $93^{\circ}$, respectively. A relatively larger contact angle for the DOTBT covered copper surface, when compared with bare copper, indicates the hydrophobic nature of the nanofilm. The degree of hydrophobicity is higher in the case of films formed by the molecules containing long alkyl chains. The hydrophobicity of the DOTBT film is comparable to that of the SAM formed by 4-aminobenzenthiol (Tan et al 2006), 2-(octadecyl thiobenzothiazole) (Appa Rao et al 2009) and 5-methoxy-2-(octadecylthio)benzimidazole (Appa Rao et al 2010). However, the contact angle of DOTBT modified copper is lower than the contact angle of octadecanethiol (ODT) SAM on copper surface (Petrovic et al 2008). The reason is that the adsorbed DOTBT molecule is considered to be oriented parallel to the copper surface, while the ODT molecule is oriented perpendicular to 


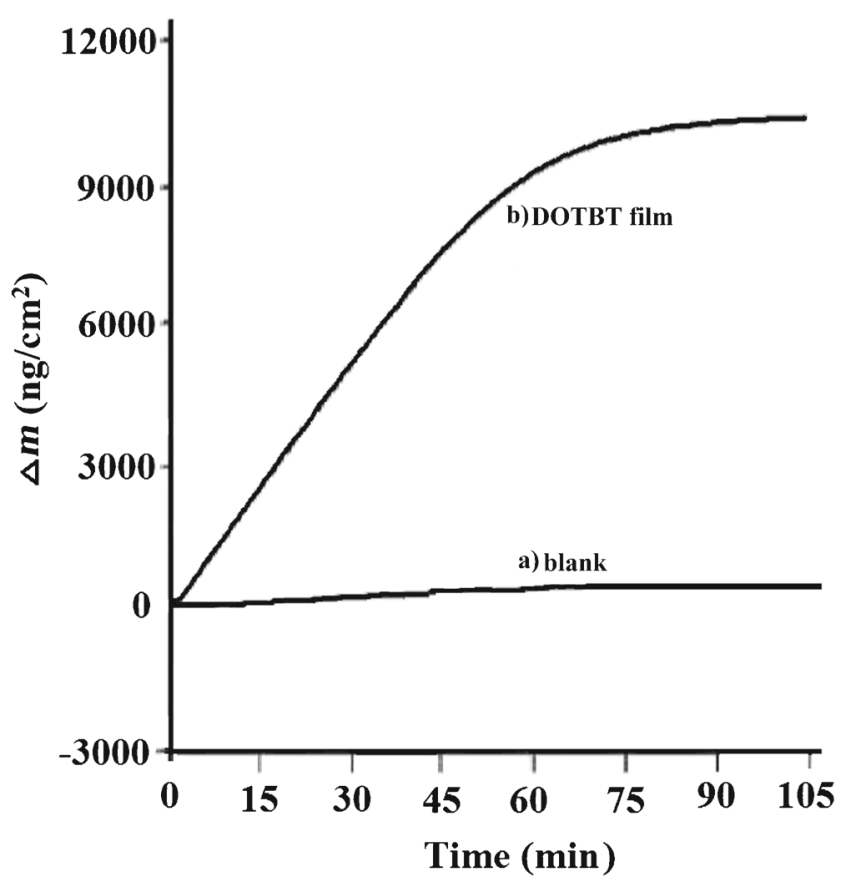

Figure 4. Mass change vs time curves obtained by quartz crystal nano balance (a) blank and (b) with DOTBT film.

copper surface and hence, a relatively larger contact angle with water drop, in case of the latter.

3.2b X-ray photoelectron spectral studies: In the XPS spectrum of bare copper, the peaks due to $\mathrm{Cu} 2 p_{3 / 2}, \mathrm{Cu} 2 p_{1 / 2}$, $\mathrm{C} 1 s$ and $\mathrm{O} 1 s$ electrons are detected. The computer deconvolution spectra for copper, carbon and oxygen are shown in the figure $5(\mathrm{a}-\mathrm{c})$, respectively. The $\mathrm{Cu} 2 p_{3 / 2}$ peak at a binding energy of $932.6 \mathrm{eV}$ and the $\mathrm{Cu} 2 \mathrm{p}_{1 / 2}$ peak at $952.4 \mathrm{eV}$ can be attributed to $\mathrm{Cu}$ (I) (Wang et al 2002). The $\mathrm{C} 1$ s electron binding energy at $285 \mathrm{eV}$ corresponds to contaminant carbon, which is likely due to the cracking of vacuum oil used in the XPS instrument (Cicileo et al 1999). The O 1 s peak observed at $531 \cdot 1 \mathrm{eV}$ is due to the formation of $\mathrm{Cu}_{2} \mathrm{O}$ on the copper surface (Petkova et al 1998; Ye et al 1998), which is formed during the interval between polishing of the copper surface and the XPS analysis. In the XPS spectrum of DOTBT modified copper surface, $\mathrm{Cu} 2 p, \mathrm{O} 1 s, \mathrm{C} 1 s, \mathrm{~N} 1 s$ and $\mathrm{S} 2 p$ peaks are detected and their deconvolution spectra are shown in figure 6(a-e), respectively. The peaks at $932.5 \mathrm{eV}$ for $\mathrm{Cu} 2 p_{3 / 2}$ and at $952.4 \mathrm{eV}$ for $\mathrm{Cu} 2 p_{1 / 2}$ are due to the initial oxidation of copper surface to $\mathrm{Cu}_{2} \mathrm{O}$ during film formation. The $\mathrm{C} 1 s$ spectrum shows two peaks, one at $284.7 \mathrm{eV}$ and the other at $287.4 \mathrm{eV}$. The intense peak observed at $284.7 \mathrm{eV}$ is due to the presence of long alkyl chain in DOTBT (Hutt and Liu 2005). The other peak at $287.4 \mathrm{eV}$ is due to the carbon atoms present in the benzotriazine ring. The ratio of the intensities of the $\mathrm{C} 1 s$ peak to the $\mathrm{Cu} 2 p_{3 / 2}$ peak in the XPS spectrum of DOTBT modified copper is nearly 33 times higher than the corresponding ratio of intensities observed in the spectrum of bare copper. This result infers the presence of nanofilm of organic molecule with long alkyl chain on the copper surface. The O $1 s$ peak observed at $531.8 \mathrm{eV}$ is due to the initial oxidation of copper surface during film formation. The existence of oxygen in the film shows that the oxygen dissolved in the solution has taken part in the selfassembly process, by oxidizing the copper surface to $\mathrm{Cu}_{2} \mathrm{O}$ (Wang et al 2002). The N $1 s$ spectrum shows two peaks, one at $399.0 \mathrm{eV}$ and the other at $400.4 \mathrm{eV}$, which are due to the presence of two nitrogen atoms in DOTBT in two different chemical environments. The characteristic binding energy of the elemental nitrogen is reported at $398.0 \mathrm{eV}$ in the literature (Beccaria and Bertolotto 1997). The shift of $\mathrm{N}$ $1 s$ binding energy from elemental binding energy indicates that the nitrogen atoms present in DOTBT play a vital role in complex formation between copper and DOTBT. The S $2 p$ spectrum shows two peaks, one at $163 \cdot 1$ and the other at $164.4 \mathrm{eV}$, which are due to $\mathrm{S} 2 p_{3 / 2}, \mathrm{~S} 2 p_{1 / 2}$ components, respectively with a separation of $1.4 \mathrm{eV}$. This infers the presence of sulfur of DOTBT in the nanofilm formed on copper surface.

3.2c Reflection absorption FTIR spectral studies: Reflection absorption FTIR spectra for bare copper and the copper covered with DOTBT nanofilm are shown in figure 7(a and b), respectively. For bare copper, the spectrum shows a peak at $489.5 \mathrm{~cm}^{-1}$, which is assigned to copper oxide on the surface (Papadimitropoulos et al 2005). The DOTBT modified copper shows peaks at 2924 and $2854 \mathrm{~cm}^{-1}$, which may be interpreted due to $\mathrm{CH}_{2}$ asymmetric and $\mathrm{CH}_{2}$ symmetric stretching modes, respectively (Laibinis et al 1991; Yoshida and Ishida 1995; Silverstein and Webster 2007; Mekhalif et al 2008). Thus, there is a clear evidence of aliphatic hydrocarbon chain present in the DOTBT film formed on copper surface. The spectrum also shows the appearance of $\mathrm{C}=\mathrm{C}$ stretching band at $1605 \mathrm{~cm}^{-1}, \mathrm{C}=\mathrm{N}$ stretching band at $1452 \mathrm{~cm}^{-1}, \mathrm{C}-\mathrm{N}$ stretching band at $1274 \mathrm{~cm}^{-1}$ and $\mathrm{C}-\mathrm{S}$ stretching band at $749 \mathrm{~cm}^{-1}$ (Lalitha et al 2005). The lowering of $\mathrm{C}=\mathrm{N}$ stretching band from 1600 to $1456 \mathrm{~cm}^{-1}$ (Baba et al 1997) reveals the formation of complex between DOTBT and copper surface through nitrogen. The vibration stretching band at $530 \mathrm{~cm}^{-1}$ is due to the copper oxide formation because of initial oxidation of copper surface during film formation (Papadimitropoulos et al 2005). These peaks clearly infer the presence of DOTBT nanofilm on copper surface.

3.2d Surface analysis by atomic force microscopy: AFM images of bare copper and DOTBT-modified copper are shown in figure 8( $\mathrm{a}$ and $\mathrm{b}$ ), respectively. A homogenous thin film of copper oxides is observed on the surface of the bare copper. AFM image of the DOTBT covered copper surface shows continuous nodules covering the whole surface. This layer prevents copper surface from corrosion. 
Table 2. Impedance parameters of copper covered with DOTBT nanofilm formed at $2.5 \mathrm{mM}$ concentration of DOTBT at different immersion periods (environment: $300 \mathrm{ppm}$ chloride, immersion period: $0.5 \mathrm{~h}$, temperature: $\left.30{ }^{\circ} \mathrm{C}\right)$.

\begin{tabular}{|c|c|c|c|c|c|c|c|}
\hline S. no. & $\begin{array}{l}\text { Immersion period } \\
\text { for formation } \\
\text { of DOTBT film }(\mathrm{h})\end{array}$ & $\begin{array}{c}R_{\mathrm{ct}} \\
\left(\mathrm{k} \Omega \mathrm{cm}^{2}\right)\end{array}$ & $\begin{array}{c}\mathrm{CPE} \\
\left(\mu \mathrm{F} / \mathrm{cm}^{2}\right)\end{array}$ & $n$ & $\begin{array}{c}R_{\text {film }} \\
\left(\mathrm{k} \Omega \mathrm{cm}^{2}\right)\end{array}$ & $\begin{array}{c}\mathrm{CPE}_{\mathrm{film}} \\
\left(\mu \mathrm{F} / \mathrm{cm}^{2}\right)\end{array}$ & $n_{\text {film }}$ \\
\hline 1 & 3 & 24.98 & $0 \cdot 326$ & 0.82 & $7 \cdot 10$ & 0.055 & 0.53 \\
\hline 2 & 6 & $40 \cdot 24$ & 0.256 & 0.83 & 9.48 & 0.099 & 0.53 \\
\hline 3 & 12 & $143 \cdot 8$ & $0 \cdot 213$ & 0.86 & $42 \cdot 24$ & 0.058 & 0.65 \\
\hline 4 & 24 & $721 \cdot 3$ & 0.033 & 0.93 & $70 \cdot 22$ & 0.022 & 0.73 \\
\hline
\end{tabular}
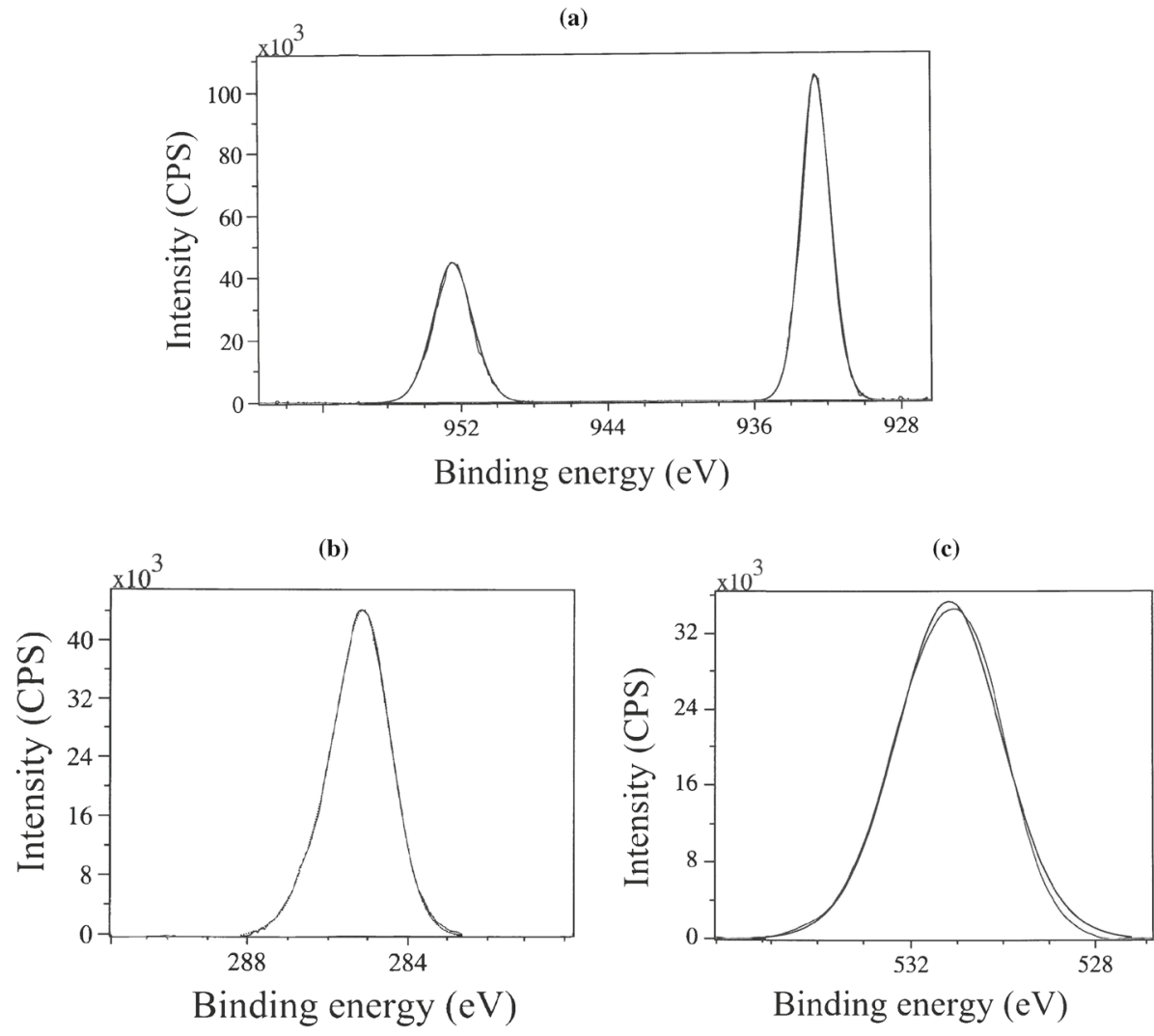

Figure 5. XPS deconvolution spectra of different elements present on the surface of bare copper $(\mathbf{a}-\mathrm{Cu} 2 p, \mathbf{b}-\mathrm{C} 1 s, \mathbf{c}-\mathrm{O} 1 s)$.

\subsection{Corrosion protection of copper by DOTBT nanofilm}

3.3a Electrochemical impedance studies: The Bode plots of bare copper and copper covered with DOTBT film are obtained in different concentrations of $\mathrm{NaCl}$ solutions $(0 \cdot 02-$ $0.20 \mathrm{M}$ ) at constant immersion period of $0.5 \mathrm{~h}$ and are shown in figure $9(\mathrm{a}$ and $\mathrm{b})$. The corresponding impedance parameters are shown in table 3. The EIS data of bare copper in $\mathrm{NaCl}$ solution are best fitted by using the equivalent circuit shown in figure 2(c), whereas for the copper electrode covered with DOTBT film, the EIS data are best fitted with the equivalent circuit shown in figure 2(b).

The Bode plots of bare copper exhibit a phase angle maximum of $45^{\circ}$ and a slope of $-1 / 2$ for $\log |Z|$ vs $\log f$ in the medium frequency region. This is the characteristic of Warburg impedance indicating diffusion effect (Gracias 2005). In the Bode plots of DOTBT-modified copper, the phase angle maximum is increased to $80^{\circ}$ and is shifted towards higher frequency side. This result indicates that it is closer to capacitive behaviour. The total impedance is increased to a much higher value after the film formation. The CPE values are decreased, the $n$ values are increased and $R_{\mathrm{ct}}$ values are enormously increased in presence of DOTBT film on the copper surface. For example, in $0.02 \mathrm{M} \mathrm{NaCl}$ environment, the $R_{\mathrm{ct}}$ value has enormously increased from $2.60 \mathrm{k} \Omega \mathrm{cm}^{2}$ in case of bare copper to $401.4 \mathrm{k} \Omega \mathrm{cm}^{2}$ for copper covered with DOTBT film in the same environment. The CPE decreased from 4.00 to $0.15 \mu \mathrm{F} / \mathrm{cm}^{2}$ and $n$ value has increased from 

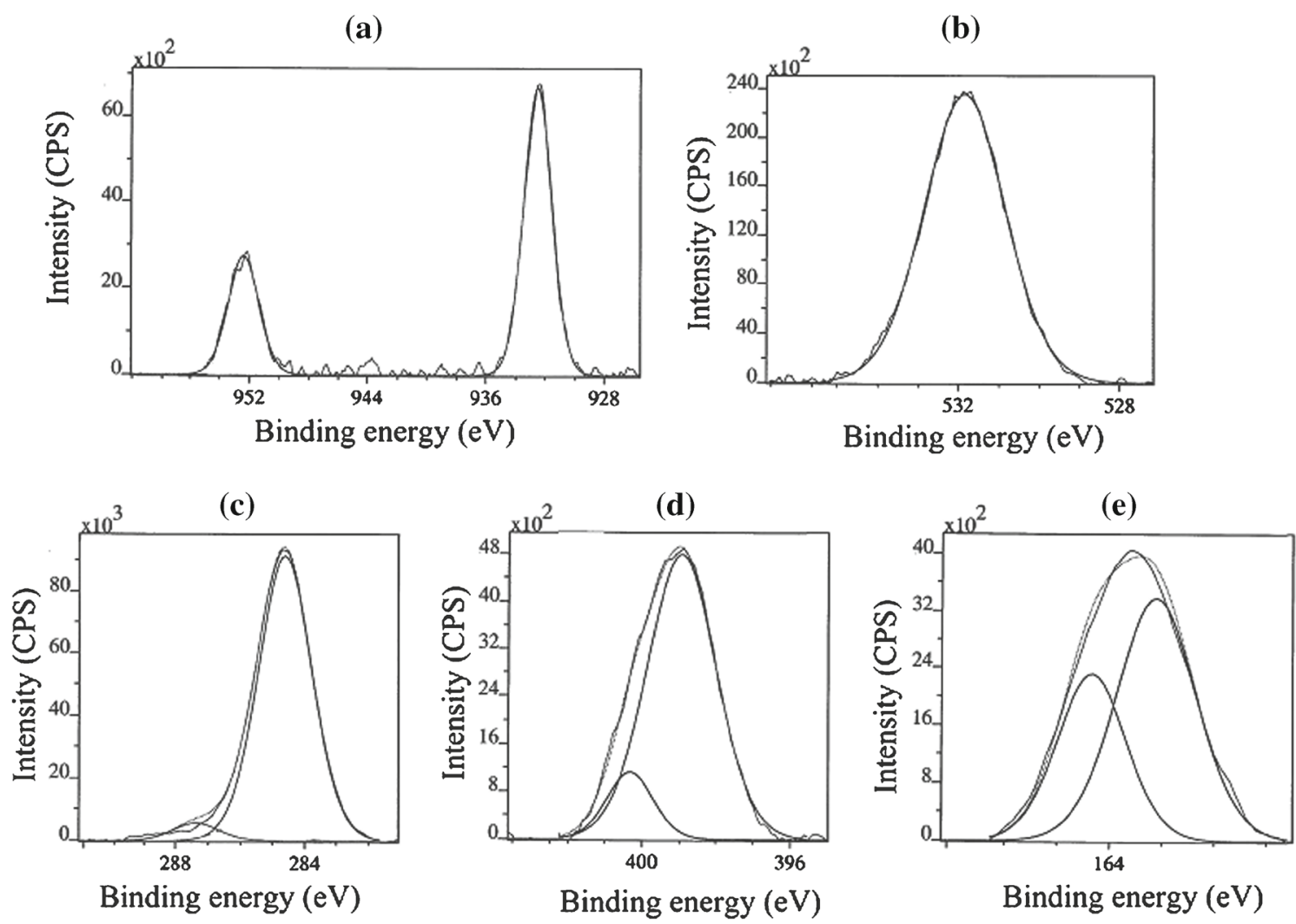

Figure 6. XPS deconvolution spectra of different elements present on the surface of copper covered with DOTBT nanofilm $(\mathbf{a}-\mathrm{Cu} 2 p, \mathbf{b}-\mathrm{O} 1 s, \mathbf{c}-\mathrm{C} 1 s, \mathbf{d}-\mathrm{N} 1 s, \mathbf{e}-\mathrm{S} 2 p)$.

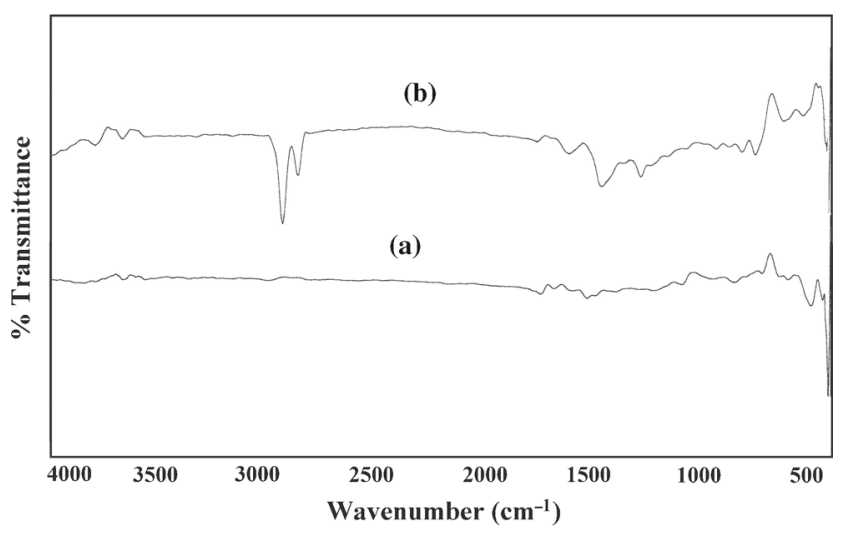

Figure 7. Reflection absorption FTIR spectra of (a) bare copper and (b) copper covered with DOTBT nanofilm.

0.46 to $0 \cdot 84$. The increase in $n$ value indicates that the surface becomes smoother after the formation of the DOTBT film. Inhibition efficiencies are found to be in the range of 99.4-96.2\% within the concentration range studied.

The Bode plots of bare copper and copper covered with DOTBT film are obtained in $0.02 \mathrm{M} \mathrm{NaCl}$ solution at different immersion periods $(0 \cdot 5-24 \mathrm{~h})$ and are shown in figure $10(\mathrm{a}$ and $\mathrm{b})$. The corresponding impedance parameters are shown in table 4 . The $R_{\mathrm{ct}}$ values of DOTBT-modified copper are much higher than those of bare copper at all immersion periods studied. The value of $n$ at various immersion periods has not changed much. This shows that the homogeneity of the protective film is maintained even after an immersion period of $24 \mathrm{~h}$. Inhibition efficiencies are in the range of $99.4-97.3 \%$ in $0.02 \mathrm{M} \mathrm{NaCl}$ environment within the range of immersion times studied.

The Bode plots of bare copper and DOTBT-modified copper are obtained in $0.02 \mathrm{M} \mathrm{NaCl}$ solution at different temperatures $\left(30-60^{\circ} \mathrm{C}\right.$ ) and at a constant immersion period of $0.5 \mathrm{~h}$ and are shown in figure $11(\mathrm{a}$ and $\mathrm{b})$. The corresponding impedance parameters are shown in table 5. With increase in temperature, $R_{\mathrm{ct}}$ values decreased for both bare copper and DOTBT-modified copper. From the literature reports, it has been inferred that with increase in temperature, corrosion rate increases in absence and presence of inhibitors (Dafali et al 2002). For the DOTBT-modified copper, the $R_{\mathrm{ct}}$ and $n$ values slightly decreased with an increase in temperature. The corrosion protection efficiencies of the films are found to be in the range of $99.4-96.9 \%$ within the temperature range studied.

3.3b Potentiodynamic polarization studies: Potentiodynamic polarization curves for bare copper and DOTBTmodified copper are obtained in $\mathrm{NaCl}$ solution over a concentration range of $0 \cdot 02-0.20 \mathrm{M}$ after an immersion period of $0.5 \mathrm{~h}$ and are shown in figure 12( $\mathrm{a}$ and b), respectively, and the corresponding corrosion parameters are given in 

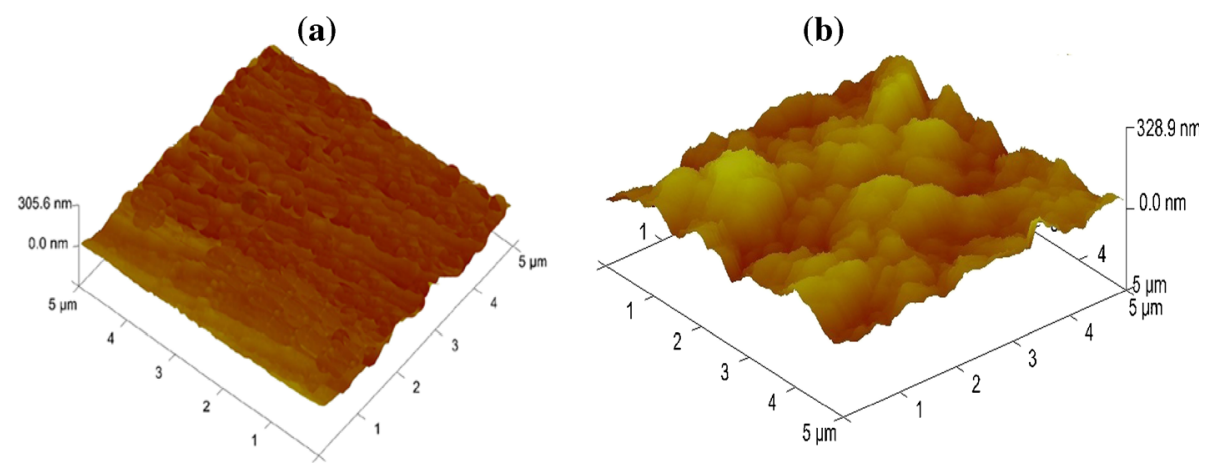

Figure 8. AFM images of (a) bare copper and (b) DOTBT nanofilm covered copper.
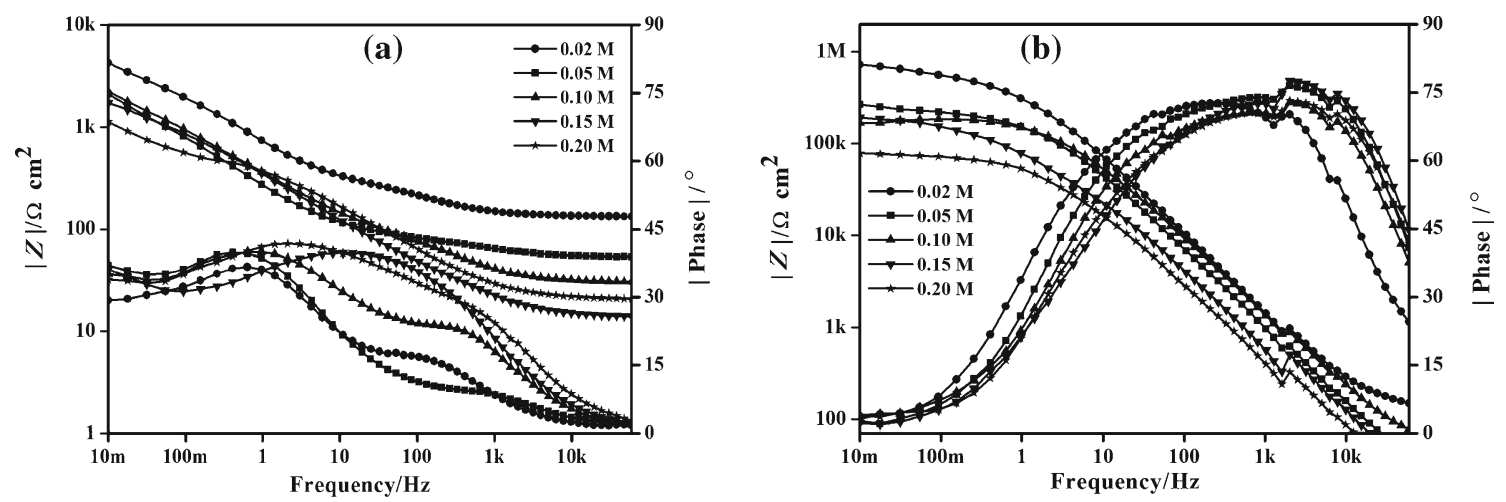

Figure 9. Bode plots of (a) bare copper and (b) DOTBT film covered copper in different concentrations of $\mathrm{NaCl}$ (immersion period: $0.5 \mathrm{~h}$, temperature: $30^{\circ} \mathrm{C}$ ).

Table 3. Impedance parameters of bare copper and copper covered with DOTBT nanofilm in $\mathrm{NaCl}$ environment at different concentrations (immersion period: $0 \cdot 5 \mathrm{~h}$, temperature: $30^{\circ} \mathrm{C}$ ).

\begin{tabular}{|c|c|c|c|c|c|c|c|c|c|}
\hline S. no. & Specimen & Conc. (M) & $R_{\mathrm{ct}}\left(\mathrm{k} \Omega \mathrm{cm}^{2}\right)$ & $\mathrm{CPE}\left(\mu \mathrm{F} / \mathrm{cm}^{2}\right)$ & $n$ & $R_{\text {film }}\left(\mathrm{k} \Omega \mathrm{cm}^{2}\right)$ & $\mathrm{CPE}_{\text {film }}\left(\mu \mathrm{F} / \mathrm{cm}^{2}\right)$ & $n_{\text {film }}$ & $\operatorname{IE}(\%)$ \\
\hline 1 & Bare copper & 0.02 & $2 \cdot 60$ & $4 \cdot 00$ & 0.46 & - & - & - & - \\
\hline 2 & Copper with DOTBT film & 0.02 & $401 \cdot 4$ & $0 \cdot 14$ & $0 \cdot 84$ & $218 \cdot 3$ & $0 \cdot 095$ & $0 \cdot 64$ & $99 \cdot 4$ \\
\hline 3 & Bare copper & $0 \cdot 05$ & $2 \cdot 27$ & $5 \cdot 91$ & 0.46 & - & - & - & - \\
\hline 4 & Copper with DOTBT film & 0.05 & $136 \cdot 7$ & $0 \cdot 12$ & $0 \cdot 85$ & $98 \cdot 83$ & $0 \cdot 147$ & $0 \cdot 61$ & $98 \cdot 3$ \\
\hline 5 & Bare copper & $0 \cdot 10$ & $2 \cdot 01$ & $8 \cdot 58$ & $0 \cdot 42$ & - & - & - & - \\
\hline 6 & Copper with DOTBT film & $0 \cdot 10$ & $112 \cdot 4$ & $0 \cdot 11$ & $0 \cdot 83$ & 77.08 & $0 \cdot 080$ & $0 \cdot 62$ & $98 \cdot 2$ \\
\hline 7 & Bare copper & $0 \cdot 15$ & 1.96 & $8 \cdot 04$ & $0 \cdot 38$ & - & - & - & - \\
\hline 8 & Copper with DOTBT film & $0 \cdot 15$ & $98 \cdot 25$ & $0 \cdot 13$ & $0 \cdot 84$ & $48 \cdot 44$ & $0 \cdot 020$ & $0 \cdot 60$ & $98 \cdot 0$ \\
\hline 9 & Bare copper & $0 \cdot 20$ & 1.89 & $11 \cdot 16$ & $0 \cdot 38$ & - & - & - & - \\
\hline 10 & Copper with DOTBT film & $0 \cdot 20$ & $50 \cdot 14$ & $0 \cdot 15$ & $0 \cdot 80$ & $25 \cdot 10$ & $0 \cdot 156$ & $0 \cdot 60$ & $96 \cdot 2$ \\
\hline
\end{tabular}

table 6. At all the concentrations, the $i_{\text {corr }}$ values are found to decrease in case of DOTBT-modified copper, when compared with bare copper. The corrosion potential is shifted towards negative side, after formation of film on copper surface. The cathodic Tafel slope $\left(b_{c}\right)$ is shifted to a greater extent than anodic Tafel slope $\left(b_{\mathrm{a}}\right)$, after formation of nanofilm on copper surface. For example, in $0.02 \mathrm{M} \mathrm{NaCl}$, the $b_{\mathrm{c}}$ value is shifted from -433 to $-62 \mathrm{mV} / \mathrm{dec}$, whereas, $b_{\text {a }}$ value is shifted from 80 to $69 \mathrm{mV} / \mathrm{dec}$ only. From these observations, it is inferred that the cathodic reaction of corrosion process is controlled more effectively by the DOTBT film on copper surface in $\mathrm{NaCl}$ solutions. It is evident from the literature reports that the nanofilms formed on copper surface inhibit cathodic reaction more significantly than the anodic reaction (Ma et al 2003; Bereket et al 2007). Corrosion inhibition efficiencies are calculated from $i_{\text {corr }}$ values and are found to be in the range of $99.7-93.3 \%$ within the concentration range studied. 

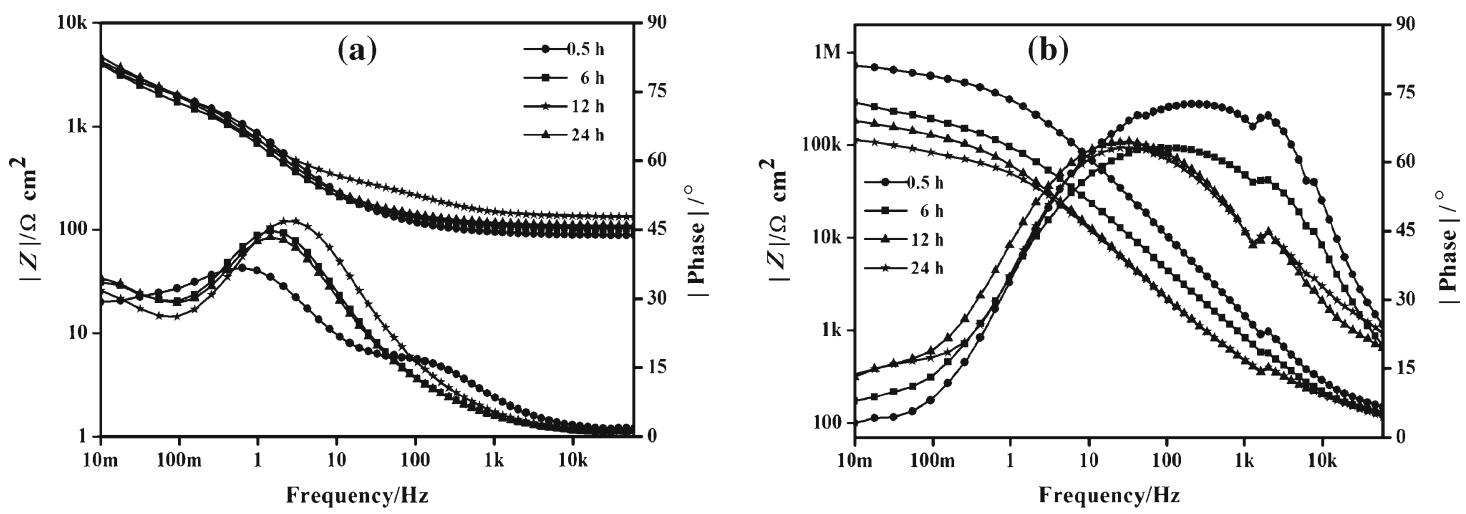

Figure 10. Bode plots of (a) bare copper and (b) DOTBT film covered copper in $0.02 \mathrm{M} \mathrm{NaCl}$ at different immersion periods (temperature: $30^{\circ} \mathrm{C}$ ).

Table 4. Impedance parameters of bare copper and copper covered with DOTBT nanofilm in 0.02 $\mathrm{M} \mathrm{NaCl}$ environment at different immersion periods (temperature: $30^{\circ} \mathrm{C}$ ).

\begin{tabular}{|c|c|c|c|c|c|c|c|c|c|}
\hline S. no. & Specimen & $\begin{array}{l}\text { Immersion } \\
\text { time (h) }\end{array}$ & $\begin{array}{c}R_{\mathrm{ct}} \\
\left(\mathrm{k} \Omega \mathrm{cm}^{2}\right)\end{array}$ & $\begin{array}{c}\mathrm{CPE} \\
\left(\mu \mathrm{F} / \mathrm{cm}^{2}\right)\end{array}$ & $n$ & $\begin{array}{c}R_{\mathrm{film}} \\
\left(\mathrm{k} \Omega \mathrm{cm}^{2}\right)\end{array}$ & $\begin{array}{c}\mathrm{CPE}_{\mathrm{film}} \\
\left(\mu \mathrm{F} / \mathrm{cm}^{2}\right)\end{array}$ & $n_{\text {film }}$ & $\mathrm{IE}(\%)$ \\
\hline 1 & Bare copper & 1 & $2 \cdot 60$ & $4 \cdot 00$ & 0.46 & - & - & - & - \\
\hline 2 & Copper with DOTBT film & 1 & $401 \cdot 4$ & $0 \cdot 14$ & $0 \cdot 84$ & $218 \cdot 3$ & 0.095 & 0.64 & 99.4 \\
\hline 3 & Bare copper & 6 & $2 \cdot 58$ & $6 \cdot 81$ & 0.46 & - & - & - & - \\
\hline 4 & Copper with DOTBT film & 6 & $163 \cdot 6$ & $0 \cdot 18$ & 0.74 & $119 \cdot 4$ & $0 \cdot 223$ & $0 \cdot 50$ & $98 \cdot 4$ \\
\hline 5 & Bare copper & 12 & $2 \cdot 46$ & $7 \cdot 30$ & 0.45 & - & - & - & - \\
\hline 6 & Copper with DOTBT film & 12 & $139 \cdot 1$ & $0 \cdot 31$ & $0 \cdot 72$ & $41 \cdot 2$ & $0 \cdot 374$ & 0.44 & $98 \cdot 2$ \\
\hline 7 & Bare copper & 24 & $2 \cdot 42$ & 8.93 & 0.45 & - & - & - & - \\
\hline 8 & Copper with DOTBT film & 24 & $89 \cdot 8$ & $0 \cdot 30$ & $0 \cdot 70$ & $8 \cdot 4$ & 0.53 & 0.42 & $97 \cdot 3$ \\
\hline
\end{tabular}
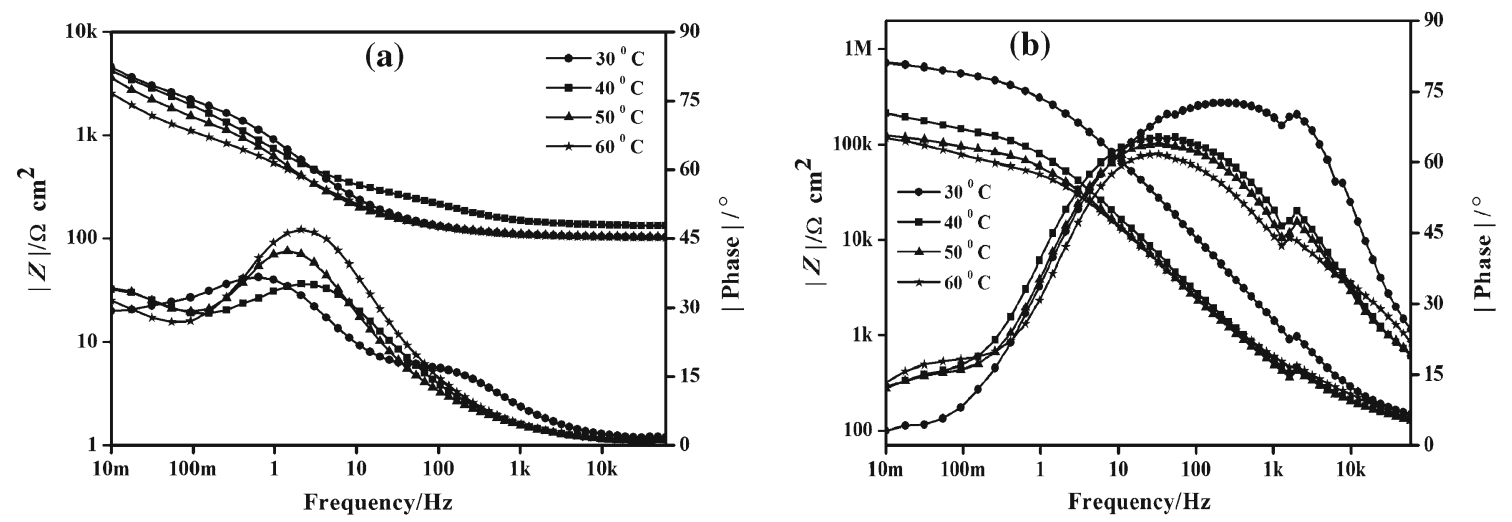

Figure 11. Bode plots of (a) bare copper and (b) DOTBT film covered copper in $0.02 \mathrm{M} \mathrm{NaCl}$ after $0.5 \mathrm{~h}$ immersion period at different temperatures.

3.3c Results of studies using electrochemical quartz crystal nanobalance: Figure 13( $\mathrm{a}$ and $\mathrm{b}$ ) show the mass change vs time curves obtained from EQCN experiment for the bare copper quartz crystal and DOTBT covered copper quartz crystal in $0.02 \mathrm{M} \mathrm{NaCl}$ environment. After immersion up to $24 \mathrm{~h}$, a mass change of $-17 \mu \mathrm{g} / \mathrm{cm}^{2}$ is observed for bare copper quartz crystal. The film covered copper quartz crystal showed a very less mass change of $-0.35 \mu \mathrm{g} / \mathrm{cm}^{2}$ and the inhibition efficiency of the DOTBT-modified copper is found to be $97.9 \%$. These results infer that the DOTBT nanofilm is protective in nature in $\mathrm{NaCl}$ environment.

3.3d X-ray photoelectron spectral studies: In the XPS survey spectrum of bare copper after immersion in $0.02 \mathrm{M}$ $\mathrm{NaCl}$ environment for 3 days, $\mathrm{Cu} 2 p_{3 / 2}, \mathrm{Cu} 2 p_{1 / 2}$ and $\mathrm{O} 1 s$ peaks are detected, along with $\mathrm{Cl} 2 p$ peak at $199.8 \mathrm{eV}$. The 
Table 5. Impedance parameters of bare copper and copper covered with DOTBT nanofilm in 0.02 $\mathrm{M} \mathrm{NaCl}$ environment at different temperatures (immersion period: $0.5 \mathrm{~h}$ ).

\begin{tabular}{|c|c|c|c|c|c|c|c|c|c|}
\hline S. no. & Specimen & $\begin{array}{c}\text { Temperature } \\
\left({ }^{\circ} \mathrm{C}\right)\end{array}$ & $\begin{array}{c}R_{\mathrm{ct}} \\
\left(\mathrm{k} \Omega \mathrm{cm}^{2}\right)\end{array}$ & $\begin{array}{c}\mathrm{CPE} \\
\left(\mu \mathrm{F} / \mathrm{cm}^{2}\right)\end{array}$ & $n$ & $\begin{array}{c}R_{\mathrm{film}} \\
\left(\mathrm{k} \Omega \mathrm{cm}^{2}\right)\end{array}$ & $\begin{array}{l}\mathrm{CPE}_{\mathrm{film}} \\
\left(\mu \mathrm{F} / \mathrm{cm}^{2}\right)\end{array}$ & $n_{\text {film }}$ & $\mathrm{IE}(\%)$ \\
\hline 1 & Bare copper & 30 & $2 \cdot 60$ & $4 \cdot 00$ & 0.46 & - & - & - & - \\
\hline 2 & Copper with DOTBT film & 30 & $401 \cdot 4$ & $0 \cdot 14$ & $0 \cdot 84$ & $218 \cdot 3$ & 0.095 & $0 \cdot 64$ & $99 \cdot 4$ \\
\hline 3 & Bare copper & 40 & $2 \cdot 50$ & 5.79 & 0.45 & - & - & - & - \\
\hline 4 & Copper with DOTBT film & 40 & $126 \cdot 6$ & $0 \cdot 25$ & $0 \cdot 72$ & $63 \cdot 64$ & 0.052 & $0 \cdot 60$ & $98 \cdot 0$ \\
\hline 5 & Bare copper & 50 & $2 \cdot 44$ & $7 \cdot 71$ & 0.45 & - & - & - & - \\
\hline 6 & Copper with DOTBT film & 50 & $85 \cdot 6$ & $0 \cdot 28$ & $0 \cdot 70$ & $44 \cdot 06$ & $0 \cdot 121$ & $0 \cdot 60$ & $97 \cdot 2$ \\
\hline 7 & Bare copper & 60 & $2 \cdot 40$ & $8 \cdot 84$ & $0 \cdot 41$ & - & - & - & - \\
\hline 8 & Copper with DOTBT film & 60 & $77 \cdot 2$ & $0 \cdot 20$ & $0 \cdot 64$ & $18 \cdot 97$ & $0 \cdot 188$ & 0.55 & $96 \cdot 9$ \\
\hline
\end{tabular}
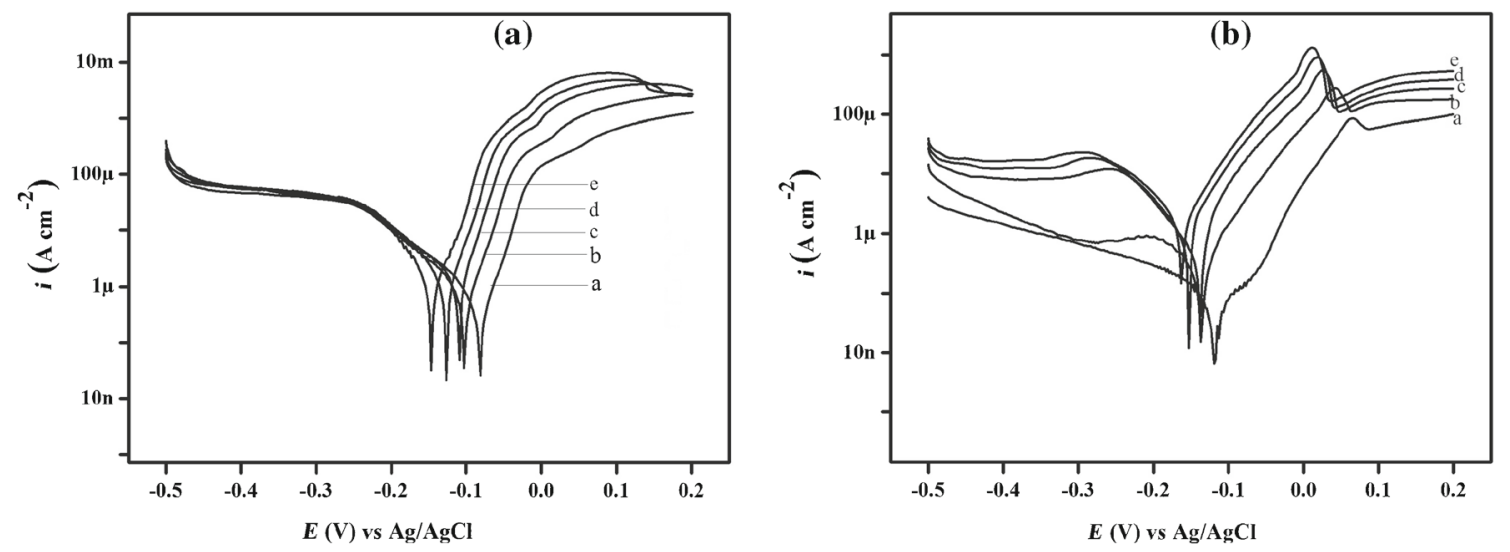

Figure 12. Potentiodynamic polarization curves of (a) bare copper and (b) DOTBT nanofilm covered copper in different concentrations of $\mathrm{NaCl}(\mathbf{a}-0.02 \mathrm{M}, \mathbf{b}-0.05 \mathrm{M}, \mathbf{c}-0.10 \mathrm{M}, \mathbf{d}-0.15 \mathrm{M}, \mathbf{e}-0.20 \mathrm{M}$ and (immersion period: $0.5 \mathrm{~h}$, temperature: $30^{\circ} \mathrm{C}$ ).

Table 6. Corrosion parameters obtained by potentiodynamic polarization studies of bare copper and copper covered with DOTBT nanofilm in $\mathrm{NaCl}$ environment at different concentrations (immersion period: $0.5 \mathrm{~h}$, temperature: $30{ }^{\circ} \mathrm{C}$ ).

\begin{tabular}{|c|c|c|c|c|c|c|c|}
\hline S. no. & Specimen & $\mathrm{NaCl}$ conc. $(\mathrm{M})$ & $E_{\text {corr }}(\mathrm{mV})$ & $i_{\text {corr }}\left(\mu \mathrm{A} / \mathrm{cm}^{2}\right)$ & $b_{\mathrm{a}}(\mathrm{mV} /$ decade $)$ & $b_{\mathrm{c}}(\mathrm{mV} /$ decade $)$ & $\operatorname{IE}(\%)$ \\
\hline 1 & Bare copper & 0.02 & $-83 \cdot 4$ & $11 \cdot 9$ & 80 & -433 & - \\
\hline 2 & Copper with DOTBT film & 0.02 & $-118 \cdot 5$ & $0 \cdot 04$ & 69 & -62 & 99.7 \\
\hline 3 & Bare copper & $0 \cdot 05$ & $-99 \cdot 6$ & $14 \cdot 1$ & 64 & -442 & - \\
\hline 4 & Copper with DOTBT film & $0 \cdot 05$ & $-135 \cdot 9$ & $0 \cdot 16$ & 34 & -64 & $98 \cdot 9$ \\
\hline 5 & Bare copper & $0 \cdot 10$ & $-108 \cdot 6$ & $16 \cdot 0$ & 52 & -456 & - \\
\hline 6 & Copper with DOTBT film & $0 \cdot 10$ & $-139 \cdot 6$ & 0.44 & 29 & -66 & $97 \cdot 3$ \\
\hline 7 & Bare copper & $0 \cdot 15$ & $-128 \cdot 7$ & $17 \cdot 2$ & 56 & -419 & - \\
\hline 8 & Copper with DOTBT film & $0 \cdot 15$ & -152.9 & $0 \cdot 81$ & 32 & -69 & $95 \cdot 3$ \\
\hline 9 & Bare copper & $0 \cdot 20$ & $-147 \cdot 0$ & $19 \cdot 6$ & 60 & -427 & - \\
\hline 10 & Copper with DOTBT film & $0 \cdot 20$ & $-160 \cdot 6$ & $1 \cdot 31$ & 46 & -68 & $93 \cdot 3$ \\
\hline
\end{tabular}

peaks due to $\mathrm{Cu} 2 p$ and $\mathrm{O} 1 s$ are similar to those shown in figure 5(a and b) (before immersion in $0.02 \mathrm{M} \mathrm{NaCl}$ ). The peaks infer the formation of $\mathrm{Cu}_{2} \mathrm{O}$. The computer deconvolution spectrum for $\mathrm{Cl} 2 p$ is shown in figure 14. This peak is due to the formation of $\mathrm{CuCl}_{2}$ on copper surface.

The XPS spectrum of the copper covered with DOTBT nanofilm after immersion in $0.02 \mathrm{M} \mathrm{NaCl}$ environment for
$3 \mathrm{~d}$ shows peaks related to $\mathrm{Cu} 2 p, \mathrm{O} 1 s, \mathrm{C} 1 s, \mathrm{~N} 1 s$ and $\mathrm{S}$ $2 p$. The $\mathrm{Cl} 2 p$ peak is absent. The computer deconvolution spectra are shown in figure $15(\mathrm{a}-\mathrm{e})$, respectively. These spectra are compared with the corresponding spectra shown in figure 6(a-e), for the DOTBT-modified copper substrate before immersion in the said corrosive environment. The intensities of $\mathrm{C} 1 s$ and $\mathrm{O} 1 s$ peaks have not changed. $\mathrm{Cu} 2 p$, 

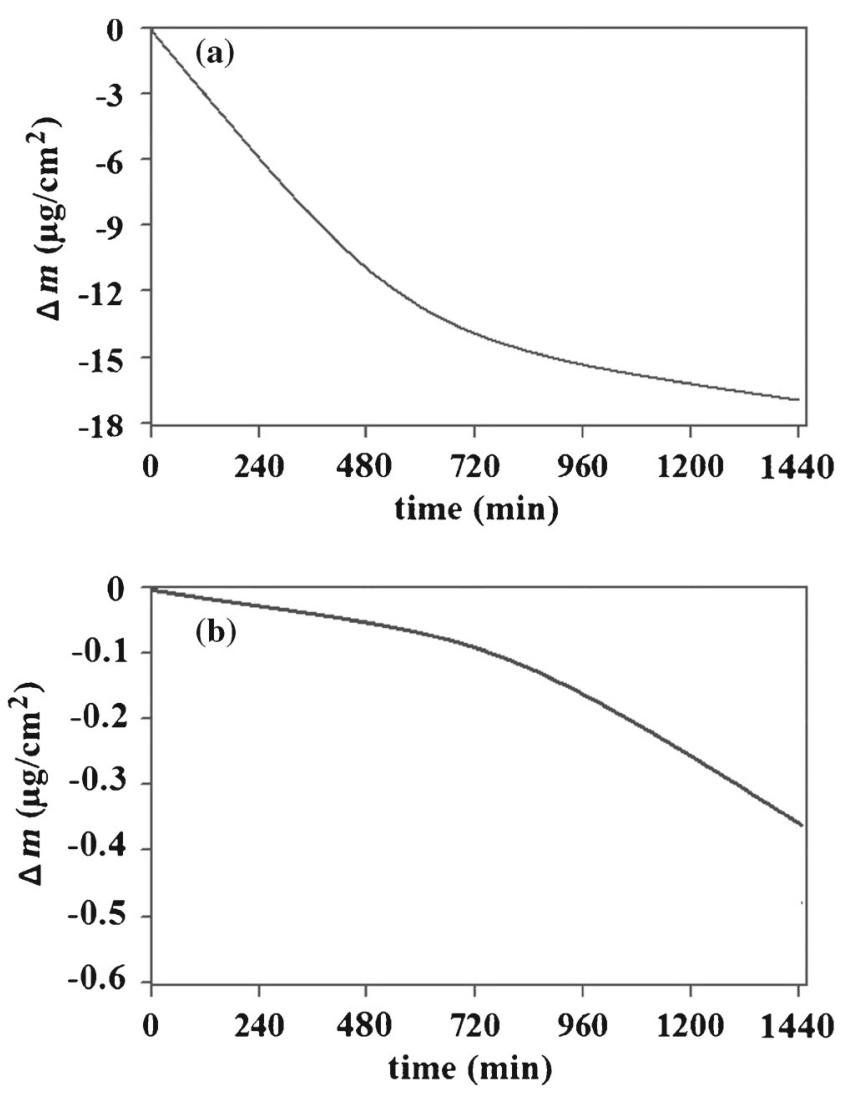

Figure 13. Mass change vs time curve on copper quartz crystal in $0.02 \mathrm{M} \mathrm{NaCl}$. (a) Bare copper and (b) DOTBT nanofilm covered copper.

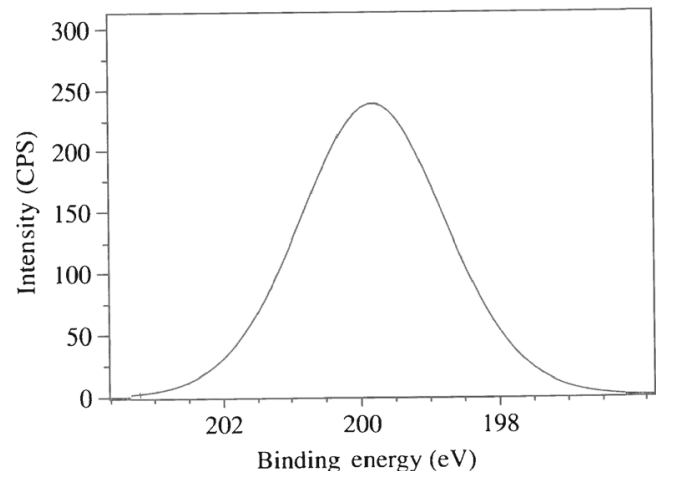

Figure 14. XPS deconvolution spectrum of $\mathrm{Cl} 2 p$ present on the surface of the bare copper after immersion in $0.02 \mathrm{M} \mathrm{NaCl}$ solution for a period of 3 days.

$\mathrm{N} 1 s$ and $\mathrm{S} 2 p$ peak intensities have slightly decreased. These studies infer that the DOTBT nanofilm is stable on copper surface even after $3 \mathrm{~d}$ immersion period in $0.02 \mathrm{M} \mathrm{NaCl}$ environment.

3.3e Results of weight-loss studies: In $0.02 \mathrm{M} \mathrm{NaCl}$ environment after an immersion period of $3 \mathrm{~d}$, corrosion rates of $0.0641 \mathrm{~mm} / \mathrm{yr}$ for bare copper and of $0.0036 \mathrm{~mm} / \mathrm{yr}$ for copper covered with DOTBT film are obtained. An inhibition efficiency of $94.3 \%$ is obtained from the data. These results show that the corrosion prevention of copper by DOTBT nanofilm is excellent in the $\mathrm{NaCl}$ environment, even after an immersion period of $3 \mathrm{~d}$.

3.3f Results of quantum chemical calculations: Inhibitors can form coordinate bonds with metal atoms through the unshared electron pair present on the nitrogen atom and also with $\pi$ electrons of the aromatic ring. The higher the negative atomic charges on the adsorbed centre, the more easily it can donate its electrons to the unoccupied orbital of the metal (Wang et al 2003). Chemisorption of DOTBT molecules on copper surface can be explained in terms of higher HOMO energy $(-6.841 \mathrm{eV})$, small energy gap $(5.005 \mathrm{eV})$ between LUMO and HOMO and a high negative total ring charge $(-1.640)$ of the DOTBT molecule.

\section{Mechanistic aspects of corrosion protection by DOTBT nanofilm}

In the absence of DOTBT nanofilm, anodic dissolution of copper in chloride environment proceeds via a two-step oxidation process (Scheider 1975).

$$
\begin{aligned}
& \mathrm{Cu}+\mathrm{Cl}^{-} \rightarrow \mathrm{CuCl}+e^{-}, \\
& \mathrm{CuCl}+\mathrm{Cl}^{-} \rightarrow \mathrm{CuCl}_{2}^{-} .
\end{aligned}
$$

The $\mathrm{CuCl}$ has poor adhesion and is unable to protect the copper surface and transforms into the soluble cuprous chloride complex, $\mathrm{CuCl}_{2}^{-}$(Yan et al 2000). The cathodic corrosion reaction in acidic chloride environment (Zhang et al 2005) is

$$
4 \mathrm{H}^{+}+\mathrm{O}_{2}+4 e^{-} \rightarrow 2 \mathrm{H}_{2} \mathrm{O} \text {. }
$$

A plausible mechanism for corrosion protection of copper by DOTBT nanofilm is discussed subsequently. The DOTBT molecules get chemisorbed on the copper surface and form a chelate with $\mathrm{Cu}^{+}$ions on the surface as shown in figure 16 . One of the reasons for relatively lower contact angle value of DOTBT SAM in comparison with ODT SAM is that the DOTBT molecules are oriented parallel to the metal surface. The DOTBT molecules get chemisorbed on the copper surface and form a monolayer. The subsequent layers are formed due to secondary forces of attraction such as hydrogen bonding and $\pi$-stack interactions between the DOTBT molecules. Thus, there is a definite possibility of formation of multilayer at least at certain locations as evidenced by AFM. There is also a possibility of pinhole distribution, which is a general feature of any SAM. The large negative charge of the ring favours the formation of a coordinate linkage between DOTBT and $\mathrm{Cu}^{+}$ions available on the copper surface, through the nitrogen atoms present in the triazine ring. Thus, there is formation of a $\left[\mathrm{Cu}^{+}-\right.$DOTBT $]$polymeric complex, which is highly protective in nature. 


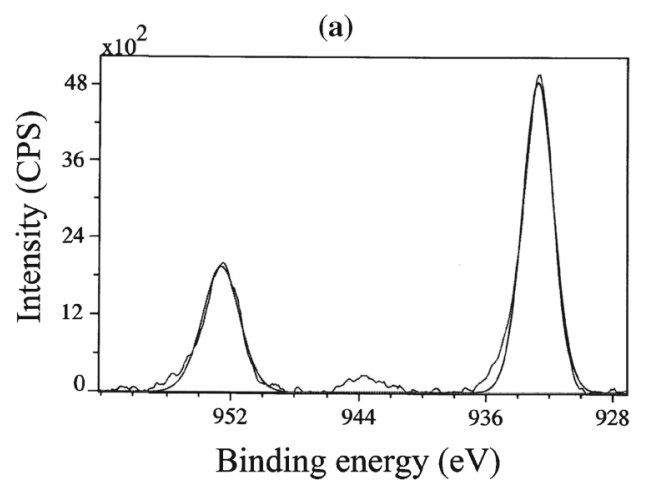

(c)

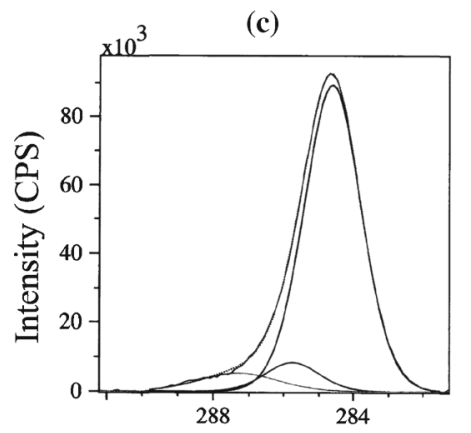

Binding energy (eV)

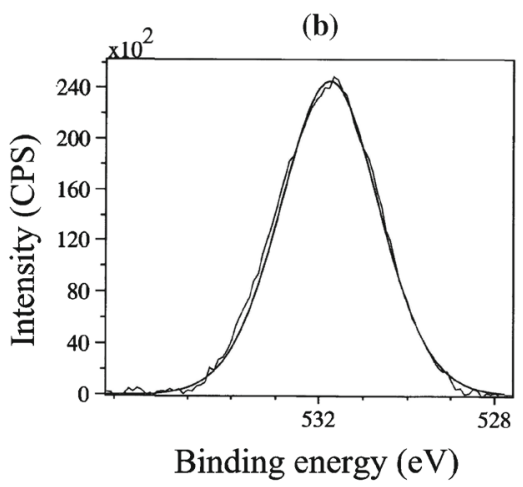

(d)

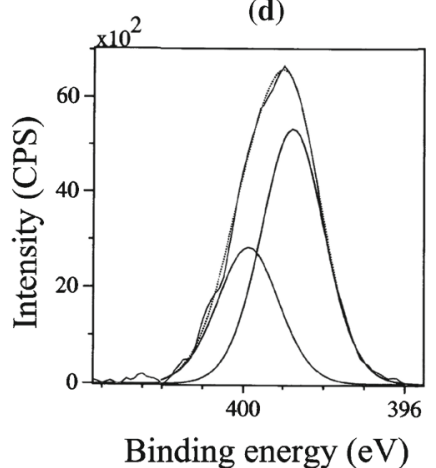

(e)

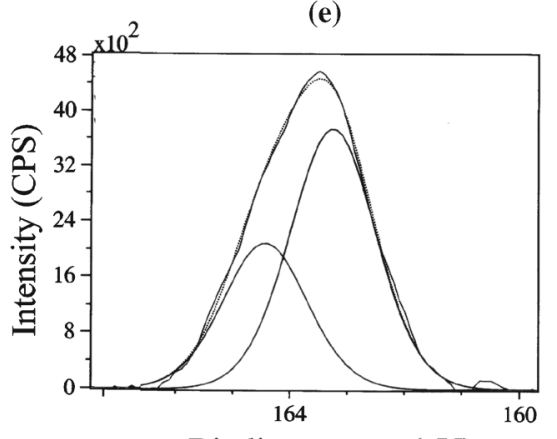

Binding energy $(\mathrm{eV})$

Figure 15. XPS deconvolution spectra of different elements present on the copper covered with DOTBT nanofilm after immersion in $0.02 \mathrm{M} \mathrm{NaCl}$ solution for a period of 3 days $(\mathbf{a}-\mathrm{Cu} 2 p, \mathbf{b}-\mathrm{O} 1 s, \mathbf{c}-\mathrm{C} 1 s, \mathbf{d}-\mathrm{N} 1 s, \mathbf{e}-\mathrm{S} 2 p)$.

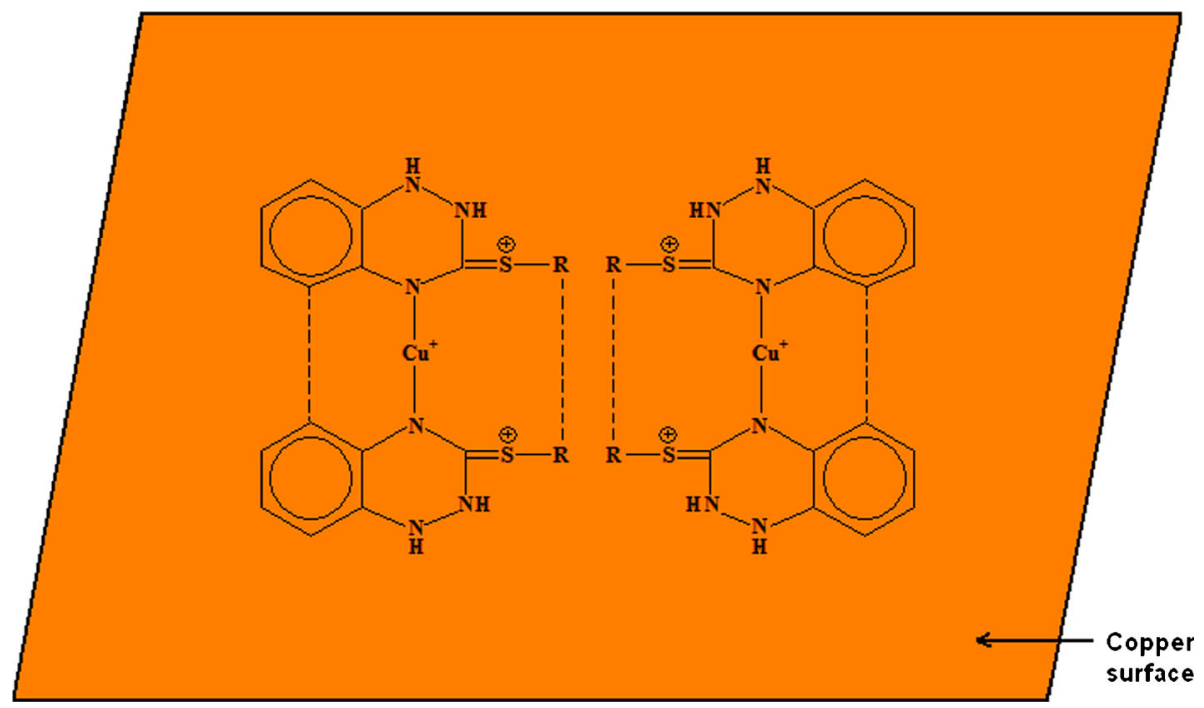

Figure 16. Schematic of formation of protective nanofilm by DOTBT on copper surface. Complex formation between $\mathrm{Cu}^{+}$ions and DOTBT molecules oriented parallel to copper surface is shown.

\section{Limitations of SAMs}

(I) Some problems arise when molecules are self assembled on continuously changing surfaces or metals covered with unstable, porous oxides. This causes disordering of the adsorption layers and consequently defects in SAMs.

(II) Choice of metal substrate to form SAM is limited.

(III) SAMs are sensitive to temperature.

(IV) SAMs may not be stable in all corrosive environments. 


\section{Conclusions}

The optimum conditions for the formation of protective nanofilm of 1,2-dihydro-3-(octadecylthio)benzotriazine on copper surface are (i) etching of copper surface in $7 \mathrm{~N}$ nitric acid for $30 \mathrm{~s}$, (ii) methanol as solvent, (iii) $2.5 \mathrm{mM}$ concentration of DOTBT in methanol, (iv) immersion time of $24 \mathrm{~h}$ and (v) ambient temperature of $30^{\circ} \mathrm{C}$. The nanofilm formed by DOTBT on copper surface offers excellent corrosion protection of copper in $\mathrm{NaCl}$ solution within the concentration range $(0.02-0.20 \mathrm{M})$, immersion period $(0.5-24 \mathrm{~h})$ and temperature range $\left(30-60{ }^{\circ} \mathrm{C}\right)$ studied. The inhibition efficiencies obtained from weight-loss studies, electrochemical impedance studies, polarization studies and quartz crystal nano balance studies are in good agreement with each other. The DOTBT molecules get chemisorbed on copper surface and form a polymeric coordination complex with $\mathrm{Cu}^{+}$ions through nitrogen atoms.

\section{Acknowledgement}

The authors are thankful to the National Institute of Technology Warangal, India, for providing necessary facilities for carrying out this research work.

\section{References}

Appa Rao B V, Yakub Iqbal Md and Sreedhar B 2009 Corros. Sci. 511441

Appa Rao B V, Yakub Iqbal Md and Sreedhar B 2010 Electrochim. Acta $\mathbf{5 5} 620$

Baba H, Kodama T, Mori K and Hirahara H 1997 Corros. Sci. 39 555

Beccaria A M and Bertolotto C 1997 Electrochim. Acta 421361

Bereket G, Pakdil S, Aldemir and Ogretir C 2007 Corros. Engg. Sci. Technol. 42253

Brzoska J B, Shahidzadeh N and Rondelez F 1992 Nature 360719

Cicileo G P, Rosales B M, Varela F E and Vilche J R 1999 Corros. Sci. 411359

Dafali A, Hammouti B, Touzani R, Kertit S, Ramdani A and El Kacemi K 2002 Anti-Corros. Methods Mater. 4996

Feng Y Q, Teo W K, Siow K S, Gao Z Q, Tan K L and Hsieh A K 1997 J. Electrochem. Soc. 14455
Freeman R A and Silverman D C 1992 Corros. 48463

Gracias D H 2005 US Patent 6858527

Hutt D A and Liu C 2005 Appl. Surf. Sci. 252400

Laibinis P E and Whitesides G M 1992 J. Am. Chem. Soc. 1149022

Laibinis P E, Whitesides G M, Allara D L, Tao Y-T, Parikh A N and Nuzzo R G 1991 J. Am. Chem. Soc. 1137152

Lalitha A, Ramesh S and Rajeswari S 2005 Electrochim. Acta 5147

Ma H Y, Yang C, Yin B S, Li G Y, Chen S H and Luo J L 2003 Appl. Surf. Sci. 218143

Macdonald D D, Mckubre M C H, Bockris J O M, Conway B E and White R E 1982 in Modern aspects of electrochemistry (New York: Plenum Press)

Mc Cafferty E 1997 Corros. Sci. 39243

Mekhalif Z, Fonder G, Laffineur F and Delhalle J 2008 J. Electroanal. Chem. 621245

Murarka S P 1997 Mater. Sci. Eng. R 1987

Papadimitropoulos G, Vourdas N, Em Vamvakas V and Davazoglou D 2005 J. Phys. Conf. Series 10182

Petkova G, Sokolova E, Raicheva S and Ivanov P 1998 J. Appl. Electrochem. 281067

Petrovic Z, Hukovic M M and Babic R 2008 Prog. Org. Coat. 611

Quan Z, Wu X, Chen S, Zhao S and Ma H 2001 Corros. 57195

Quan Z, Chen S, Cui X and Li Y 2002 Corros. 58248

Rao V R and Kumar V R 2002 Ind. J. Chem. Sect. B 41B 415

Rose J W 2002 Power Energy: Proc. Inst. Mech. Eng. Part A 215 115

Scheider W 1975 J. Phys. Chem. 79127

Silverstein R M and Webster F X 2007 Spectroscopic identification of organic compounds (New Delhi: Wiley India (P) Ltd.) 6th Wiley student edn

Tan Y S, Srinivasan M P, Pehkonen S O and Simon Chooi Y M 2006 Corros. Sci. 48840

Touzet M, Cid M, Puiggali M and Petit M C 1993 Corros. Sci. 34 1187

Wang C T, Chen S H, Ma H Y, Hua L and Wang N X 2002 J. Serb. Chem. Soc. 67685

Wang C T, Chen S H, Ma H Y and Qi C S 2003 J. Appl. Electrochem. 33179

Wu X, Ma H, Chen S, Xu Z and Sui A 1999 J. Electrochem. Soc. 1461847

Yamamoto Y, Nishihara H and Aramaki K 1993 J. Electrochem. Soc. 140436

Yan C W, Lin H C and Cao C N 2000 Electrochim. Acta 452815

Ye X R, Xin X Q, Zhu J J and Xue Z L 1998 Appl. Surf. Sci. 135307

Yoshida S and Ishida H 1995 Appl. Surf. Sci. 8939

Zhang D Q, Gao L X and Zhou G D 2005 J. Appl. Electrochem. 35 1081 